\title{
Methods and Rules of Voting and Decision: A Literature Review
}

\author{
Danting Zhang \\ School of Administrative Management, Jinan University, Guangzhou, China \\ Email: zhdting@126.com
}

How to cite this paper: Zhang, D.T. (2020) Methods and Rules of Voting and Decision: A Literature Review. Open Journal of Social Sciences, 8, 60-72.

https://doi.org/10.4236/jss.2020.81005

Received: December 12, 2019

Accepted: January 5, 2020

Published: January 8, 2020

Copyright $\odot 2020$ by author(s) and Scientific Research Publishing Inc. This work is licensed under the Creative Commons Attribution International License (CC BY 4.0).

http://creativecommons.org/licenses/by/4.0/

\begin{abstract}
Based on introducing the definition and some relative conceptions about voting and decision, this article focuses on presenting the factors that influence people's voting and decision making behaviors. Then several common voting rules and methods are summarized respectively. After introducing voting models, the application of voting and decision rules are discussed.
\end{abstract}

\section{Keywords}

Voting Rule, Voting Method, Decision Making

\section{Introduction}

In 2018, the reality TV show "Create 101" ended successfully with a total broadcast volume of more than 4.73 billion. The huge social influence brought by it made the program be evaluated as "phenomenon pop variety show" by the media. "Creation 101" comes from the South Korean program named "Produce 101 ", which is a draft class reality show, in which the audience votes to decide the members. Different from the voting mechanism of previous talent shows, which is mainly based on the voting of professional judges, the program put forward the concept of "the founder of the whole people" from the very beginning, and the audience voted to decide the players to stay. The voting mechanism in the program is also different from that in the past: ordinary users of Tencent video have 11 votes a day, while VIP users have 121 votes of voting privilege; in addition, when purchasing a customized membership card for players, one can also vote for another 121 votes. In the face of the incentive policy of voting mechanism, the enthusiasm of the audience to participate in voting interaction is very high, which not only brings considerable economic benefits to the platform, but also causes the academic research on voting behavior.

Voting is an important way to make group decisions. Voting or social choice 
rules are different methods of aggregation of decision makers' votes for their preferred options and have been proposed for developing transparency and fairness (Nurmi, 2010) [1]. Voting methods are normally simple to understand and appreciate by a large group of decision makers and the general public. So, they do not cause in mistrust of the decision makers (Gregory, 2002) [2], who might find mathematically sophisticated MCDM, game theory, and bargaining methods somewhat confusing.

Voting methods do not require detailed quantitative information as they rely on ordinal information, i.e. voters' expressed preference orders over the alternatives. This makes the decision process quick, transparent, and convenient to handle even in large groups (Kangas et al., 2007) [3]. Additionally, methods that rely on ordinal ranking information are less sensitive to the uncertainty in input information when such information is provided in quantitative (cardinal) terms, making them less controversial and more robust in practice (Madani and Lund 2011) [4].

\section{Conceptions and Theories about Voting and Decision}

\subsection{The Nature of Voting and Decision}

Uncertainty is integral to voting and decision making. Uncertainty could be internal-relating to the decision makers' notions and judgments (Isendahl et al., 2009) [5], or external-relating to the imperfect information of the problem (Figueira et al., 2005) [6]. Ignoring the uncertainties involved in different components of a decision making problem, most importantly in input information, can result in misleading outcomes. A responsible and comprehensive decision making analysis must inform the stakeholders about the effects of the involved uncertainties on the selected decision and its risk of failure.

Uncertainty in environmental decision making problems have been mainly handled through sensitivity analysis, fuzzy decision analysis, and Monte-Carlo selection approaches. The first two methods use stochastic inputs to generate deterministic output, and thus do not fully inform the decision maker about the magnitude of risk associated with the selected outcomes. Sensitivity analysis evaluates internal uncertainty by altering performance measures and weights to test the feasibility of solutions. The fuzzy problem solving approach assumes that stakeholders' preferences have some uncertainty that can be evaluated at different degrees to evaluate its impact on the decision (Rastgoftar et al., 2012) [7]. The latter method helps with mapping uncertainties from input to output while simplifying it. Therefore, instead of eliminating uncertainties from the outputs, outcomes are given in a probabilistic form, informing the stakeholders about the risks directly associated with decision analysis outputs and the outcomes they may select [8].

\subsection{Some Conceptions about Voting and Decision Making}

\subsubsection{Voter Turnout}

In psychological explanations of voter turnout, most of the electorate is moti- 
vated to vote by some mix of personal appeals and encouragement by the media. When a particular election becomes particularly "salient" to you (because of publicity, and possibly a connection to an issue of personal interest), you are more likely to vote. Turnout is higher in Presidential elections because they receive the most publicity; similarly for close elections, where the act of voting receives more positive pre-election publicity. The other side of the psychological-political explanation is that turnout is affected by political advertising and other partisan and bipartisan efforts at persuasion [9].

Gerber, Hoffman et al. test the relationship between voter turnout and perceived closeness of the election by conducting a experiment during the 2010 US gubernatorial elections. They elicit voter beliefs about the closeness of the election before and after showing different polls, which indicate a close race or a not close race. The result shows that subjects update voters' beliefs in response to new information, but systematically overestimate the probability of a very close election. However, the decision to vote is unaffected by beliefs about the closeness of the election. A follow-up field experiment, conducted during the 2014 gubernatorial elections but at much larger scale, also points to little relationship between poll information about closeness and voter turnout [10].

\subsubsection{Voting Paradox}

Voting Paradox (also known as Condorcet's paradox or the paradox of voting) is a situation noted by the Marquis de Condorcet in the late 18th century, in which collective preferences can be cyclic, even if the preferences of individual voters are not [11]. This is paradoxical, because it means that majority wishes can be in conflict with each other. The Voting Paradox, from its nature, denies the democratic voting system, and questions a series of related theories on philosophy, politics, economics and management [12]. The Voting Paradox mechanism figure was depicted and Majority Rule was revealed to be the cause of the Voting Paradox by analyzing its reasoning process.

\subsubsection{Voting Power and Voting Weight}

The distribution of actual voting power seldom reflects the distribution of voting weights in a voting body [13]. There are two well-known and widely used indices for measuring a priori power in voting systems, the Banzhaf index and the Shapley-Shubik index. Holler (1982) proposed the adoption of randomized decision rules as a means of equating, on the average, the distribution of a priori voting power and the actual seat distribution within the voting body [14]. However, objections to the adoption of a randomized decision rule may be raised on technical or practical grounds, as well as on psychological grounds.

\subsection{Theories of Voting and Decision Making}

The theory of voting and decision making is based on the social choice theory. Which goals are the procedures intended to serve? To what extent are these reconcilable with the goals of the participants? Are the expected outcomes of pro- 
cedures likely to be welfare increasing or divisive? These are several generally accepted theories in voting and decision making:

\subsubsection{Fuzzy Set Theory}

Fuzzy set theory was first presented by Zadeh (1965) [15]. The basis of the fuzzy set theory is a membership function $\mu(\mathrm{x})$, which describes the degree by which a certain statement is true (Zimmermann, 1985) [16]. Fuzzy decision analysis can also be based on linguistic criterion values and fuzzy weights. For such a situation, fuzzy additive weighting method has been proposed (Kangas et al., 2007) [3]. For example, a statement "a tree is defoliated" can be more or less true. If we had a crisp definition, like "a tree is defoliated if it has lost at least $50 \%$ of its needles or leaves", the membership function would only have values 0 and 1 , and fuzzy sets would not be needed [17].

\subsubsection{Possibility Theory}

The possibility theory was first presented by Zadeh (1978) [18]. It is also related to the evidence theory and to degrees of belief and plausibility. Possibility theory utilises two measures attached to one event, namely "necessity measure" and "possibility measure". Both of them are membership functions, which can take values between zero and one. These two measures are related to each other.

\subsubsection{Evidence Theory}

The evidence theory was first developed by Dempster in the 1960s [19]. His work was later extended and refined by Schafer in the 1970s (Schafer, 1976) [20]. Therefore, this theory is also called the Dempster-Schafer theory (Klir and Harmanec, 1997) [21]. The theory also deals with subjective beliefs. In the evidence theory, a number between zero and one is used to describe degree of support a certain source of evidence provides for a certain proposition, i.e. the degree of belief.

\subsubsection{Candidate-Preference Translation Theory}

Candidate-preference translation theory can be divided into two parts. The first specifies the stability in vote-translation of the various individual preference orderings possible in a three-candidate race. Certain of these orderings are shift-prone or unstable. Others are inherently stable regardless of the strategic position of the voter within the electoral arena. The second part of the theory defines which strategic positions within the electoral arena encourage shift-prone or unstable voting behavior [22].

\section{Influences of Voting and Decision Making}

Voting is a way of involving oneself in the political process, which is desirable, especially if the election seems important, is getting a lot of publicity, and is being talked about.

According to the view of "Economic Man", A rational man decides to vote just as he makes all other decisions: if the return outweighs the cost, he votes: if 
not, he abstains (Downs, 1957) [23]. Many people vote implies that people do see benefits, perhaps non-pecuniary benefits, but benefits nonetheless. Since the administrative cost of voting has declined in the US, the downward trend in turnout would seem to suggest that citizens see fewer benefits from voting [24]. Rational choice leads to the paradox of voting, because voters are not willing to pay a price for voting because of their insignificant voting results. However, in the political field, in addition to the self-interest mentioned in the theory of public choice, there are also psychological benefits and personal preferences generated by civic awareness and other factors. There is a great defect in considering voters' voting behavior only from the "utilitarian factors". Without giving up the "self-interest" factors, it is the trend to study voting behavior at the same time.

From the psychological point of view of voters, foreign researchers have come to the conclusion on whether to vote: those who think their votes have a great impact on the final voting results are more likely to vote. According to Graham Wallas, unlike the traditional political thinkers, voting behavior is mostly irrational. Emotional factors affect the decision-making of voters, which leads to the weakness of political voters, that is, they are easy to be used by candidates. Through the analysis of the presidential election in 2000, the voting behavior of voters is closely related to their leadership and personality [25].

When Chinese scholars study the villagers' voting issues, they focus on institutional factors and people's consciousness, such as whether the electoral system and procedures are reasonable and fair, whether they can create benefits for voters, the education level of voters, political responsibility and obligations. In addition, the past performance of leaders and the situation of the chosen will also affect the voting decisions of the voters. According to Elster's behavioral theory of rationality, emotion and social norms, Cheng Shouyan sums up three important factors that affect voting behavior as rationality, that is rationality, sensibility and social norms, among which social norms are influenced by such factors as clan, social relations and morality [26]. When Xiao Lihui analyzed the villagers' voting behavior, he thought that age, gender and education level may also be the influencing factors of voting behavior, which will indirectly affect the rational choice of voters and their cognition of voting income [27].

All in all, the influences of voting and decision making can be summarized into five factors:

\subsection{Individual Preference}

Nurmi considers that each individual has a preference ranking over the criteria, which reduces the rule selection into the classic social choice problem and choice of the rules gets its justification from the views that the individuals have on the significance of the criteria [28]. The preferences that different decision makers entertain over rules may be different due to the different weights assigned to criteria. Using the Borda count one is able to construct a vector of weights that reflects the importance that the individuals assign to various criteria.

Koppensteiner and Stephan support previous findings that first impressions 
and self-evaluations affect voting decisions by conducting an experiment in which participants rated short video clips of politicians giving a speech. Results also indicate that when only nonverbal information is available people prefer political candidates they perceive as having personality traits they value in themselves [29].

Bensel and Anders emphasize the influence of the electoral college on presidential voting. The distinction between the candidate preferences and the revealed electoral translation is of great importance for the analysis of third-party campaigns. The "slippage" between the individual's articulated preference ordering and his actual vote is analyzed with respect to the strategic position of the voter in his state [22].

\subsection{Policy Views, Supportive Constituents and President}

Drawing on data gathered from interviews with 365congressional staff people, Burgin finds three influences in particular stand out as significant in the decision-making process of US strategy in the Persian Gulf in January 1991: members' own policy views, supportive constituents, and (for certain groups of members) the president. Thus, while the analysis confirms, the conventional view of legislators' personal policy assessments as the critical influence on foreign and defense policy votes, it also underscores that this influence does not operate in a vacuum [30].

\subsection{Education, Age and Income}

Since shareholder voting is an important instrument of corporate governance (Iliev et al., 2015, p. 2171), Schmidt sheds first light on the determinants of voting turnout at an individual level by analyzing a large and unique data set collected from a survey among almost 425,000 German retail investors of a German blue-chip company. His findings indicate that particularly investors with better resources, i.e., particularly well-educated or rather sophisticated and more experienced retail investors, are more likely to use their corporate voting right [31]. Freeman examines the pattern of change in turnout in elections and in the rate of voting of different socioeconomic groups in the US. It shows that while the changing education and income structure of the population and changes in laws and regulations that make it easier to register and to vote should have raised turnout, the proportion of the voting age population that votes has fallen. It also finds that turnout has become much more unequal by age, education, and income [24].

\subsection{Detailed Decision Process}

Singh and Roy examine how the vote decision process affects the vote choice by focusing on proximity voting, an empirically powerful but informationally demanding model of voter behavior. Holding contextual factors constant, they find that more politically knowledgeable individuals engage in a deeper and broader decision process prior to casting their ballot, and, in turn, a more detailed deci- 
sion process boosts the likelihood that one will vote proximately. In addition, they find that detailed decision processes have a stronger link with proximity voting among the most knowledgeable individuals, who are able to skillfully engage with new information [32].

\subsection{Voting Technology}

Card and Moretti use county-level data on voting technologies in the 2000 and 2004 presidential elections to test whether voting technology affects electoral outcomes. The result shows that there is a positive correlation between use of touch-screen voting and the level of electoral support for George Bush. Models for the adoption of touch-screen voting suggest it was more likely to be used in counties with a higher fraction of Hispanic and Black residents, especially in swing states [33].

\section{Voting Rules and Methods}

As early as in the middle ages, Romanlull summarized two important processes of the election. He believed that the voting process was not only the decision-making process, but also the election of voters. And the voting process should be open and used the method of Pairwise comparison [34]. After that, scholars have made a systematic study on voting rules and methods.

\subsection{Voting Rules}

Plurality rule is one of the oldest and perhaps the most commonly used social choice making methods (Madani and Dinar, 2012) [35]. This method does not need complete preference information and can determine the winning option (social choice) knowing only the most preferred option of each voter. Based on the plurality rule, the social choice solution is the alternative with the highest number of votes in favor. Based on Plurality rule, Bouton analyzes a voting system which combines the plurality rule with veto power (Veto). He fins this combination can resolve the tension between information aggregation and minority protection of Agents that wants to reform the status quo if and only if this is $\mathrm{Pa}$ reto improving. This system also combines the advantageous properties of both plurality and unanimity rules and sheds new light on the evolution of voting rules in the EU institutions and could help to inform debates about policy reforms in cases such as juries in the US [36].

Pairwise comparison of alternatives under different criteria is the basis of the Condorcet method. A strong Condorcet winner is an alternative which is able to overcome all other rivals in all pairwise comparisons. Based on Condorcet method, Condorcet proposed a modified version of the Condorcet method named Condorcet practical's method. In this modified version, the process of selecting the social choice starts with searching for the majority of support at the highest level (ranked first). If there is no majority at the first level, an alternative which receives the highest level of support (though not necessarily the majority) at the 
second level is the Condorcet's practical winner.

Then a less restricted version of strong Condorcet rule called pariwise comparion appeared. The socially optimal option based on this method is winner of pairwise comparisons by majority (based on the plurality rule) [37]. A less restricted form of plurality rule named approval voting was based on voters, which are allowed to vote for more than one alternative. Similar to the plurality rule, ranking of options is not required. Essentially, voters reveal their approved options by saying yes or no to each option. The winner is then determined based on the plurality rule [38].

Majoritarian compromise is a refinement of the median voting scheme and the majoritarian compromise winners are a subset of median voting winners (Sheikhmohammady and Madani, 2008). This rule follows the same logic as median voting, but pays a special attention to quality of support (number of supporters) besides majority. The majoritarian compromise winner must receive both the maximum and majority of votes at the highest level [39].

\subsection{Voting Methods}

Arrow's impossibility theorem, which is proved by Kenneth Arrow in 1950 (Arrow 1950), states that there is no such perfect voting method that is fully fair satisfying all the consensus desirable properties, such as majority, monotonicity, independence of irrelevant alternatives, and the Condorcet criterion. However, different voting methods are all still used.

Instant Runoff Voting (IRV) Method is a voting method in which each voter ranks the alternatives in order of his preference [40]. This procedure is repeated until an alternative exists that obtains a majority of votes among alternatives not eliminated (Lippman and David, 2012) [41]. If there is a tie for last place in numbers of votes, special tie-breaking rules are applied to select which alternative to eliminate (Magrino et al., 2011) [42]. Hybrid Condorcet-IRV method makes use of both Condorcet's pairwise comparisons principle and the IRV method, similar to the Benham method mentioned in work (Green Armytage, 2011) [43] but with some differences. The method checks if an alternative exists that beats all other alternatives by one-to-one comparison (Condorcet winner), it will be moved to the first place in a winner list (W), otherwise, the IRV method, described above, will be applied and any eliminated alternative is moved to an eliminated list (E). The Analytic Hierarchy Process (AHP) was developed in the 1970s by Saaty [44]. The AHP tool can be integrated by Group Decision Support Systems (GDSS) theory and practice within decision-making process. The Analytic Hierarchy Process (AHP) permits both subjective and objective information to be considered in a decision. AHP has tremendous potential to solve both traditional and non-traditional health care problems. Its strength as a decision-making tool is its ability to combine both subjective and objective data [45]. Thomas explores the meta-decision in the context of multicriterion group decisions, comparing two alternative procedures by building a simple multiattribute value model: group members may build individual preference orderings 
by solving the multicriterion problem on their own and then vote on the alternatives, or they may vote on the relative relevance of each criterion and then compose a group preference ordering with the results. Both procedures are confronted with an appropriate group welfare measure. According to the simulation results and the lower transaction costs, voting on the alternatives in general results in higher group welfare which should always be considered the standard procedure, but voting on criteria may be superior, if the group faces fundamental value conflicts [46].

\section{Application of Voting Methods}

Generally speaking, voting methods are more commonly used in two processes: one is selection activities; the other is decision-making of major issues. Voting behavior in selection generally refers to the behavior that voters vote on the selected person in the selection process to show their preference. The decision-making of major events involves group decision-making, which is a problem of social choice. Social choice is the behavior of social members to choose the alternative plan of the event according to their own ideas. It is a typical group decision-making, and voting is a common method of social choice. Because of the different preferences of group members, the collection of information is particularly important, and the smooth voting affects the final decision-making results. Because people often regard the voting result as the final result of group decision-making, whether the voting behavior really reflects the real will of voters affects the effectiveness of decision-making results.

From the perspective of voting scenarios, voting methods are often used in political process, corporate decision-making and committees.

\subsection{In Political Process}

Political processes, for example, senate election and voting games in European Council of Ministers, are mostly studied by scholars. Senate elections are of two types: competitive or noncompetitive. Using the Pooled Senate Election Study, Koch investigates whether voters in Senate elections utilize different criteria, or give different weight to particular criteria, as a function of the competitiveness of the election [47]. Koch finds enhanced electoral competitiveness increases the importance of assessments of presidential performance on the voting decision. These effects are particularly large for voters with high levels of educational attainment. Contrary to previous research, in highly competitive elections the role of ideological considerations is smaller than in less competitive elections. Fedeli analyzes the efficiency effects in combination with some accepted "fairness" criteria for the voting games in the European Council of Ministers (ECM) under the qualified majority voting (QMV), in comparison with hypothetical simple majority voting rules (SMV), by jointly examining voting weights and voting powers [48]. The differences between the voting weights and the voting powers increase considering the attitude of the Governments of the Member States of the ECM to form voting-blocs. Their voting powers by blocking proposals result 
in stalemates and weak compromise with likely benefits for existing well organised interest groups. And, while the power of getting a proposal approved has diminished, the veto-power has remained very high.

\subsection{In Business Decision Context}

Almeida and Nurmi propose voting procedures are not only appropriate for political elections, but also for a range of business decision problems [49]. They present a framework for aiding the choice of a voting procedure in a business organization decision context, based on a multi-criteria decision making model. The decision model has considered the following main issues: the non-compensatory rationality for the decision maker; the sequence of the decision process; the set of relevant criteria; and the evaluation matrix of properties by voting procedures. This framework may help to solve one of the most common problems in business organizations, that is selecting suppliers, in which many different group decision processes may be conducted.

\subsection{In Committees}

Annick Laruelle and Federico Valenciano offer a mathematical treatment of voting power and decision-making in committees [50]. They trace back their analysis to game theory and utility theory, propose to distinguish between two polar cases of decision-making in committees, that is: take it or leave it situation and bargaining committees. In "take it or leave it" situation, the very concept of voting power does not carry much sense. The two ingredients for understanding the decision process and result are individual preferences and the way in which the voting rule aggregates them. The choice of a voting rule may follow an egalitarian or a utilitarian principle. The "bargaining committee" framework admittedly rests on preference profiles and a voting rule, but it is rooted in a strategic context that can be either cooperative or non-cooperative. The analysis highlights the Shapley-Shubik power index as a very simple bargaining protocol.

\section{Conflicts of Interest}

The author declares no conflicts of interest regarding the publication of this paper.

\section{References}

[1] Nurmi, H. (2010) Voting Theory. Springer Netherlands, Berlin, 101-123. https://doi.org/10.1007/978-90-481-9045-4_7

[2] Gregory, R.S. (2002) Incorporating Value Trade-Offs into Community-Based Environmental Risk Decisions. Environmental Values, 11, 461-488. https://doi.org/10.3197/096327102129341181

[3] Kangas, A., Leskinen, P. and Kangas, J. (2007) Comparison of Fuzzy and Statistical Approaches in Multicriteria Decision-Making. Forest Science, 53, 37-44.

[4] Madani, K. and Lund, J.R. (2011) A Monte-Carlo Game Theoretic Approach for Multi-Criteria Decision Making under Uncertainty. Advances in Water Resources, 
34, 607-616. https://doi.org/10.1016/j.advwatres.2011.02.009

[5] Isendahl, N., Dewulf, A., Brugnach, M., et al. (2009) Assessing Framing of Uncertainties in Water Management Practice. Water Resources Management, 23, 3191-3205. https://doi.org/10.1007/s11269-009-9429-y

[6] Figueira, J., Greco, S., Ehrogott, M., et al. (2018) Multiple Criteria Decision Analysis: State of the Art Surveys. International, 142, 192-202.

[7] Rastgoftar, H., Imen, S. and Madani, K. (2012) Stochastic Fuzzy Assessment for Managing Hydro-Environmental Systems under Uncertainty and Ambiguity. Proceedings of the 2012 World Environmental and Water Resources Congress, Albuquerque, 20-24 May 2012, 2413-2421. https://doi.org/10.1061/9780784412312.244

[8] Madani, K., Read, L. and Shalikarian, L. (2014) Voting under Uncertainty: A Stochastic Framework for Analyzing Group Decision Making Problems. Water Resources Management, 28, 1839-1856. https://doi.org/10.1007/s11269-014-0556-8

[9] Edlin, A.S., Gelman, A. and Kaplan, N. (2007) Voting as a Rational Choice: Why and How People Vote to Improve the Well-Being of Others. Rationality \& Society, 1, 293-314. https://doi.org/10.1177/1043463107077384

[10] Gerber, A., Hoffman, M., Morgan, J., et al. (2017) One in a Million: Field Experiments on Perceived Closeness of the Election and Voter Turnout. NBER Working Papers. https://doi.org/10.3386/w23071

[11] Yang, S. (2009) A Voting Statistical Method of Group Decision. In: International Joint Conference on Computational Sciences \& Optimization, IEEE, Piscataway, 873-875. https://doi.org/10.1109/CSO.2009.310

[12] Saari, D.G. (2008) Disposing Dictators, Demystifying Voting Paradoxes. Mathematical and Computer Modelling, 48, 1671-1673.

https://doi.org/10.1016/j.mcm.2008.05.016

[13] Berg, S. and Holler, M.J. (1986) Randomized Decision Rules in Voting Games: A Model for Strict Proportional Power. Quality and Quantity, 20, 419-429.

https://doi.org/10.1007/BF00123089

[14] Holler, M.J. (1981) An Introduction to the Analysis of Power, Voting, and Voting Power. In: Holler, M.J., Ed., Power, Voting, and Voting Power, Physica-Verlag HD, Heidelberg, 15-30. https://doi.org/10.1007/978-3-662-00411-1

[15] Zadeh, L.A. (1965) Fuzzy Sets. Information \& Control, 8, 338-353. https://doi.org/10.1016/S0019-9958(65)90241-X

[16] Zimmermann, H.-J. (1985) Fuzzy Set Theory and Its Applications. Kluwer-Nijhoff Pub., Boston. https://doi.org/10.1007/978-94-015-7153-1

[17] Kangas, A., Kangas, J. and Kurttila, M. (2008) Decision Support for Forest Management. Springer, Berlin.

[18] Zadeh, L.A. (1978) Fuzzy Sets as a Basis for a Theory of Possibility. Fuzzy Sets and Systems, 1, 3-28. https://doi.org/10.1016/0165-0114(78)90029-5

[19] Dempster, A.P. (1967) Upper and Lower Probabilities Induced by a Multivalued Mapping. Annals of Mathematical Statistics, 38, 325-339.

[20] Diaconis, R.B.P. (1978) A Mathematical Theory of Evidence. Journal of the American Statistical Association, 73, 677-678. https://doi.org/10.2307/2286624

[21] Klir, G.J. and Harmanec, D. (1997) Types and Measures of Uncertainty. In: Kacprzyk, J., Nurmi, H. and Fedrizzi, M., Eds., Consensus under Fuzziness, Springer, Berlin, 29-51. https://doi.org/10.1007/978-1-4615-6333-4_3

[22] Bensel, R.F. and Sanders, M.E. (1979) The Effect of Electoral Rules on Voting Behavior: The Electoral College and Shift Voting. Public Choice, 34, 69-85. 
https://doi.org/10.1007/BF00125754

[23] Downs, A. (1958) An Economic Theory of Government. Harper and Row, New York.

[24] Freeman, R.B. (2003) What, Me Vote? NBER Working Paper Series. https://doi.org/10.3386/w9896

[25] Pillai, R., Williams, E.A., Lowe, K.B., et al. (2003) Personality, Transformational Leadership, Trust, and the 2000 US Presidential Vote. The Leadership Quarterly, 14, 161-192. https://doi.org/10.1016/S1048-9843(03)00008-0

[26] Chen, S.Y. (2010) Rationality, Emotion and Social Norm-Three Dimensional Explanation of Villagers' Voting Behavior. Administration and Law, 3, 31-33.

[27] Xiao, L.H. (1999) An Analysis of the Factors Influencing Villagers' Voting. Journal of Shantou University, 3, 27-34.

[28] Nurmi, H. (2015) The Choice of Voting Rules Based on Preferences over Criteria. In: Kamiński, B., Kersten, G.E. and Szapiro, T., Eds., Outlooks and Insights on Group Decision and Negotiation, Springer International Publishing, Berlin, 241-252. https://doi.org/10.1007/978-3-319-19515-5_19

[29] Koppensteiner, M. and Stephan, P. (2014) Voting for a Personality: Do First Impressions and Self-Evaluations Affect Voting Decisions? Journal of Research in Personality, 51, 62-68. https://doi.org/10.1016/j.jrp.2014.04.011

[30] Burgin, E. (1994) Influences Shaping Members. Decision Making: Congressional Voting on the Persian Gulf War. Political Behavior, 16, 319-342. https://doi.org/10.1007/BF01498954

[31] Schmidt, A. (2017) Determinants of Corporate Voting-Evidence from a Large Survey of German Retail Investors. Schmalenbach Business Review, 18, 71-103. https://doi.org/10.1007/s41464-016-0024-5

[32] Singh, S.P. and Roy, J. (2014) Political Knowledge, the Decision Calculus, and Proximity Voting. Electoral Studies, 34, 89-99. https://doi.org/10.1016/j.electstud.2013.11.007

[33] Card, D. and Moretti, E. (2007) Does Voting Technology Affect Election Outcomes? Touchscreen Voting and the 2004 Presidential Election. Review of Economics \& Statistics, 89, 660-673. https://doi.org/10.1162/rest.89.4.660

[34] Mclean, I. (1990) The Borda and Condorcet Principles: Three Medieval Application. Social Choice and Welfare, 7, 99-108. https://doi.org/10.1007/BF01560577

[35] Madani, K. and Dinar, A. (2013) Cooperative Institutions for Sustainable Common Pool Resource Management: Application to Groundwater. Water Resources Research, 2-3, 57-76. https://doi.org/10.1016/j.wre.2013.08.001

[36] Bouton, L., Llorentesaguer, A. and Malherbe, F. (2014) Get Rid of Unanimity Rule: The Superiority of Majority Rules with Veto Power. CEPR Discussion Papers, 126(1). https://doi.org/10.3386/w20417

[37] Thurstone, L.L. (1927) The Method of Paired Comparisons for Social Values. The Journal of Abnormal and Social Psychology, 21, 384-400. https://doi.org/10.1037/h0065439

[38] Brams, S.J. and Fishburn, P.C. (1978) Approval Voting. The American Political Science Review, 72, 831. https://doi.org/10.2307/1955105

[39] Sertel, M.R. and YLmaz, B. (1999) The Majoritarian Compromise Is Majoritarian-Optimal and Subgame-Perfect Implementable. Social Choice \& Welfare, 16, 615-627. https://doi.org/10.1007/s003550050164

[40] Mengash, H. and Brodsky, A. (2015) A Group Package Recommender Based on 
Learning Group Preferences, Multi-Criteria Decision Analysis, and Voting. EURO Journal on Decision Processes, 3, 275-304. https://doi.org/10.1007/s40070-015-0048-y

[41] Lippman, D. (2012) Math in Society. CreatSpace Independent Publishing Platform.

[42] Magrino, T.R., Rivest, R.L., Shen, E., et al. (2011) Computing the Margin of Victory in IRV Elections. In: Conference on Electronic Voting Technology/Workshop on Trustworthy Elections, USENIX Association, Berkeley, 23-31.

[43] Armytage, G. (2011) Four Condorcet-Hare Hybrid Methods for Single-Winner Elections. Voting Matters, 29, 1-14.

[44] Saaty, T.L. (1980) The Analytic Hierarchy Process. McGraw Hill, New York. https://doi.org/10.21236/ADA214804

[45] Hatcher, M. (1994) Voting and Priorities in Health Care Decision Making, Portrayed through a Group Decision Support System, Using Analytic Hierarchy Process. Journal of Medical Systems, 18, 267-288. https://doi.org/10.1007/BF00996606

[46] Thomas, N.P. (2007) Voting on Alternatives or on Criteria? The Meta-Decision on Group Decision Procedures. In: Uncertainty and Risk, Springer, Berlin, Heidelberg, 207-219.

[47] Koch, J.W. (1998) Electoral Competitiveness and the Voting Decision Evidence from the Pooled Senate Election Study. Political Behavior, 20, 295-311. https://doi.org/10.1023/A:1024843714443

[48] Fedeli, S. and Forte, F. (2001) Voting Powers and the Efficiency of the Decision-Making Process in the European Council of Ministers. European Journal of Law and Economics, 12, 5-38. https://doi.org/10.1023/A:1011211225810

[49] Almeida, A.T.D. and Nurmi, H. (2015) A Framework for Aiding the Choice of a Voting Procedure in a Business Decision Context.

[50] Josselin, J.M. (2010) Annick Laruelle and Federico Valenciano: Voting and Collective Decision-Making: Bargaining and Power. Public Choice, 143, 259-261. https://doi.org/10.1007/s11127-009-9518-8 